\title{
From the Editor of Sexuality and Disability: A Revitalized Voice is Being Heard Around the World
}

\author{
Sigmund Hough
}

Published online: 2 August 2013

(C) Springer Science+Business Media New York 2013

The continued increase in our journal's 2012 Impact Factor and Citations highlights a revitalized voice between readership and authorship in the area of sexuality and disability. The significant increase of our Editorial Board Members this year highlights professional dedication in the area of sexuality and disability. The continued support from Springer and the wonderful talented staff highlights commitment in the area of sexuality and disability.

As I write this Editorial Note, I am sadly informed that Virginia Johnson, the pioneering sex researcher who was part of the pioneering team Masters and Johnson has died at age 88. Dr. William Masters and Johnson conducted the inaugural modern research on sexuality and the treatment of sexual dysfunction that paved the way for the sexual revolution in America. Together they published several classic books, for example, "Human Sexual Response" in 1966 and "Human Sexual Inadequacy" in 1970. Now almost half a century later from their book in 1966, the mission to understand, help and educate society continues. For many, the interest and importance has increased. For countless, the fear has decrease or been eliminated. Most importantly, we whisper the words "sexuality" and "disability" less. Gratitude to those involved in making this difference.

Sexuality and Disability continues to provide original impact articles addressing the mental health and medical aspects of sexuality in relation to rehabilitation, hospital, academic and community settings, publishing up-to-date articles, case studies, clinical practice reports, reviews, featured articles, historical articles, special grand rounds topics, brief research reports and survey data reports. Value benefit is provided to authors through worldwide electronic exposure and professional access, while readership gains from scholarly contributions to advance the field through research, best-practice and educational articles. The refined lens of individual contributions from the local and international community continues to deliver a wealth of information on the topic of sexuality and disability for the reader. Welcome, and thank you for joining $u s$.

S. Hough $(\bowtie)$

396 Washington Street, Suite 211, Wellesley Hills, MA 02481, USA

e-mail: Sigmund_Hough@hms.harvard.edu 